\title{
Triptolide induces apoptosis through the SERCA 3 upregulation in PC12 cells
}

\author{
Olga Krizanova ${ }^{1}$, Jana Markova ${ }^{1}$, Karel Pacak ${ }^{2}$, Ludovit Skultety $^{3}$, Andrea Soltysova ${ }^{1}$ \\ and Sona Hudecova ${ }^{1}$ \\ ${ }^{1}$ Institute of Molecular Physiology and Genetics, Center of Excellence for Studying Metabolic Aspects of Development, \\ Diagnostics and Treatment of the Oncologic Diseases, Slovak Academy of Sciences, Bratislava, Slovak Republic \\ ${ }^{2}$ Program in Reproductive and Adult Endocrinology, Eunice Kennedy Shriver National Institute of Child Health and Human \\ Development, National Institutes of Health, Bethesda, Maryland 20892, USA \\ ${ }^{3}$ Institute of Virology, Slovak Academy of Sciences, Bratislava, Slovak Republic
}

\begin{abstract}
Diterpenoid triepoxide - Triptolide (TTL) - increased protein levels of the noradrenaline transporter in three pheochromocytoma cell lines. This transporter is involved in the apoptosis induction through the inhibition of a transcription factor NF-kappa B. Nevertheless, calcium release from the endoplasmic reticulum can also induce inner, mitochondrial pathway of apoptosis in variety of cells. Therefore, the aim of this work was to evaluate an involvement of calcium and, more specifically, intracellular calcium transport systems in the apoptosis induction in pheochrocytoma cell line PC12. We observed significantly increased amount of reticular calcium in TTL-treated cells compared to control, untreated cells. Surprisingly, gene expression of the $\mathrm{IP}_{3}$ receptors was not changed after the TTL treatment, but ryanodine receptor of the type 2 (RyR2) was downregulated and sarco/endoplasmic reticulum calcium ATPase type 3 (SERCA 3) was upregulated in TTL- treated cells, compared to untreated controls. SERCA 3 blocking with the specific blocker thapsigargin prevented increase in apoptosis observed by the TTL treatment. Decrease in the ATP production by a replacement of glucose in the cultivation medium for its non-utilizable analog 2-deoxyglucose also prevented induction of the apoptosis in TTL-treated PC12 cells. Thus, these results suggest that upregulation of the SERCA 3 is ultimately involved in the TTL-induced apoptosis in PC12 cells.
\end{abstract}

Key words: Triptolide - Calcium transport - SERCA 3 - Apoptosis

\section{Introduction}

Triptolide (TTL), a diterpene triepoxide isolated from the herb Trypterigium Wilfordii exhibits strong anti-inflammatory effects (Lee et al. 2012; Ku and Lin, 2013; Wen et al. 2013) and also anti-tumor activity in various types of cancer cells, e.g. pheochromocytoma (Pacak et al. 2012), colon cancer (Wang et al. 2009), prostate cancer (Huang et al. 2012), ovarian cancer (Cai et al. 2013) neuroblastoma (Krosch et al. 2013), cholangiocarcinoma (Clawson et al. 2010), breast cancer (Yang et al. 2003), etc. Structure-activity relationship

Correspondence to: Sona Hudecova, Institute of Molecular Physiology and Genetics, Slovak Academy of Sciences, Vlarska 5, 83334 Bratislava, Slovak Republic

E-mail: sona.hudecova@savba.sk studies indicate that different pharmacophores are required for the various biological effects of TTL. While disruption of the 12, 13 epoxide group or C-14 hydroxyl group of TTL has been reported to eliminate its anti-inflammatory or immunosuppressive functions (Yu et al. 1992), the 9, 11 epoxide was deemed necessary for its antitumor effect (Kupchan et al. 1974). These studies raise the question of whether the various physiological effects of TTL (i.e., anti-inflammatory, proapoptotic) are elicited by a common mechanism of action and/or interaction with a common protein target.

TTL causes apoptosis in various tumor cell lines in a time and concentration dependent manner. Up to now, two pathways were shown as a possible target of TTL in cancer cell lines - the heat shock response (Antonoff et al. 2010; MacKenzie et al. 2013) and nuclear factor kappa B (NF-kB; Pacak et al. 2012; Krosch et al. 2013). NF- $\kappa$ B is active in most tumor 
cell lines, regulating cell survival, proliferation, angiogenesis and invasion through its transcriptional activation (Karin 2006). Several papers have clearly shown that inhibition of NF- $\kappa \mathrm{B}$ by TTL in cancer cell lines induces apoptosis and in the nude mice decreases number of metastases (Pacak et al. 2012; Krosch et al. 2013). Nevertheless, the main target of the NF- $\kappa B$ effect is still missing. Leuenroth and Crews (2005) showed that inhibition of the NF- $\kappa \mathrm{B}$ transcriptional control is calcium-independent. However, TTL-mediated calcium release was observed in polycystic kidney disease (Leuenroth et al. 2007). Also, in neuroblastoma cell lines, time and concentration-dependent increase in intracellular calcium levels with the TTL treatment was observed (Krosch et al. 2013). This suggests that elevated cytosolic calcium could be one of the terminal events and the common thread in the TTL-induced cell death.

Endoplasmic reticulum calcium homeostasis is involved in a multitude of signaling, as well as "house-keeping" functions that control cell growth, differentiation or apoptosis in every human/eukaryotic cell (Arbabian et al. 2011). There is substantial evidence that calcium fluxes occur during most forms of apoptosis and inhibition of these fluxes protects cells from death (Hanson et al. 2004). The positive feed-forward between $\mathrm{IP}_{3}$ receptor-mediated calcium release and mitochondria underlies the generation of calcium signals that accelerate the rate of cell death (for review see Lencesova and Krizanova 2012). Also, Sarco/Endoplasmic Reticulum Calcium transport ATPases (SERCA) expression levels can undergo significant changes during cell differentiation or tumorigenesis, leading to modified endoplasmic reticulum calcium storage (Arbabian et al. 2011). Thus, we propose that modulation of the reticular calcium might be another mechanism in the TTL-induced apoptosis. Therefore, we focused on determination of the TTL-modulated calcium transport systems localized on the endoplasmic reticulum and their impact on TTL-induced apoptosis in PC12 cells.

\section{Materials and Methods}

\section{Cell cultivation}

PC12 cells (German Collection of Microorganisms and Cell Cultures, Braunschweig, Germany) derived from a rat PHEO were cultured in Minimal Essential Medium of Dulbecco (DMEM; Sigma Aldrich, St. Louis, MO, USA) with high glucose $(4.5 \mathrm{~g} / \mathrm{l})$ or 2-deoxyglucose $(4.5 \mathrm{~g} / \mathrm{l})$, supplemented with 15\% fetal bovine serum (Sigma Aldrich, St. Louis, MO, USA) and penicillin (Calbiochem, USA; $100 \mathrm{U} / \mathrm{ml}$ ) and streptomycin (Calbiochem, USA; $100 \mu \mathrm{g} /$ $\mathrm{ml})$. Cells were cultured in a water-saturated atmosphere at $37^{\circ} \mathrm{C}$ and $5 \% \mathrm{CO}_{2}$.
Cell treatment with TTL, xestospongin and thapsigargin

TTL was dissolved in DMSO to a stock concentration $100 \mu \mathrm{M}$. PC12 cells were treated with a final concentration 100 nM TTL (Tocris Bioscience) for 24 hours. Xestospongin C (Calbiochem, Germany) was added to cells in a final concentration of $1 \mu \mathrm{M}$. Thapsigargin (Sigma Aldrich, St. Louis, MO, USA) was dilluted in DMSO to $100 \mu \mathrm{M}$ concentration and $1 \mu \mathrm{l}$ was added to $1 \mathrm{ml}$ of media, giving a final concentration of $100 \mathrm{nM}$.

\section{Western blot analysis}

Cells were scraped and pelleted at $1000 \times g$ for $5 \mathrm{~min}$. The pellet was then re-suspended in $10 \mathrm{mM}$ Tris- $\mathrm{HCl}, \mathrm{pH} 7.5$, $1 \mathrm{mM}$ phenylmethyl sulfonylfluoride (PMSF, Serva, Heidelberg, Germany), protease inhibitor cocktail tablets (complete EDTA-free, Roche Diagnostics, Mannheim, Germany) and subjected to a centrifugation for $10 \mathrm{~min}$ at $3000 \times g$ and $4^{\circ} \mathrm{C}$ to remove cell debris. Proteins in the supernatant became soluble following incubation for $15 \mathrm{~min}$ at $4^{\circ} \mathrm{C}$ with $3-[(3-$ cholamidopropyl) dimethyl-ammonio] 1-propanesulfonate (CHAPS; Sigma Aldrich, St. Louis, MO, USA) added to the final concentration of $50 \mathrm{mM}$. The protein concentration of lysate was determined by the Lowry method (Lowry et al. 1951). Ten to fifty micrograms of protein extract from each sample was separated by electrophoresis on $8-16 \%$ and 4-12\% SDS - polyacrylamide gradient gels (Amersham Biosciences, UK) for 1 hour at $120 \mathrm{~V}$, and proteins were transferred to the Hybond-PVDF membrane using semidry blotting (Amersham Biosciences, UK). Membranes were blocked in 5\% non-fat dry milk in Tris-buffered saline with Tween-20 (TBS-T) for overnight at $4^{\circ} \mathrm{C}$ and then incubated for $1 \mathrm{~h}$ with the appropriate primary antibody. Following washing, membranes were incubated with secondary antibodies to mouse or rabbit IgG conjugated to horseradish peroxidase, for $1 \mathrm{~h}$ at room temperature. An enhanced chemiluminiscence detection system (Luminata Crescendo Western HRP Substrate, Millipore Corporation, Billerica, MA, USA) was used to detect bound antibody. The glyceraldehyde-3-phosphate dehydrogenase (GAPDH) signal from each sample was used as a housekeeper and control protein for the quantification. The optical density of individual bands was measured by the Kodak Image station 440 device and quantified using PCBAS 2.0 software.

Antibodies raised against the following proteins were used: Anti-SERCA 3 mouse monoclonal antibody (Sigma Aldrich, St. Louis, MO, USA) which binds to the $97 \mathrm{kDa}$ protein. In order to detect RyR2 (ryanodine type 2 receptors), we used rabbit polyclonal antibody, which recognizes $500 \mathrm{kDa}$ protein and for NET (norepinephrine transporter) we used also rabbit polyclonal antibody, which recognizes app. $69 \mathrm{kDa}$ protein (both antibodies were from Millipore 
Corporation, Europe). Bax (sc-7480) polyclonal antibody (Santa Cruz Biotechnology INC, CA, USA) and Bcl2 polyclonal antibody (Abcam, Cambridge, UK) was used. As a housekeeper for relative quantification, the mouse monoclonal antibody to GAPDH (Abcam, Cambridge, UK) was used, this binds to the $36 \mathrm{kDa}$ protein.

Determination of metaiodobenzylguanidine (MIBG) using high performance liquid chromatography (HPLC)

MIBG has been separated from the cell extracts using solid phase extraction columns SPE Supra-Clean ${ }^{\circledR}$ Cyano CN-S Columns (J. T. Baker, USA) followed by analysis on HPLC. Briefly, the SPE columns were preconditioned with methanol $(3 \mathrm{ml})$ and water $(6 \mathrm{ml})$. Then cell extract $(1 \mathrm{ml})$ was loaded, washed with water $(6 \mathrm{ml})$ followed by methanol $(6 \mathrm{ml})$, and eluted with $100 \mathrm{mM} \mathrm{HCl}$ in $\mathrm{MeOH}(3 \mathrm{ml})$. The eluate was dried out under a stream of nitrogen at $60^{\circ} \mathrm{C}$ and reconstituted in mobile phase $(200 \mu \mathrm{l})$ consisting of $25 \mathrm{mM}$ ammonium phosphate ( $\mathrm{pH} 4.0)$ in acetonitrile (80:20). An insoluble material was spun down for 2 min and supernatant transferred into autosampler's vial. HPLC had been performed on Alliance 2690 separation module equipped with 2487 dual wavelength absorbance UV detector (Waters, USA) under the control of Millenium 32 software (Waters, USA). Isocratic separation was carried out on Watrex Nucleosil 120-5 C18 250×4 mm analytical reverse phase column with flow rate $1 \mathrm{ml} / \mathrm{min}$. Calibration curve was built for $0.1-10 \mathrm{mg} / \mathrm{ml}$ concentration range of MIBG. The quantity was calculated based on peak area of detected signal at $254 \mathrm{~nm}$ after manual integration.

\section{Detection of apoptosis with Annexin V-Fluos}

Cells were collected and washed with phosphate-buffered saline (PBS) and pelleted at $1000 \times g$ for $5 \mathrm{~min}$. A cell pellet from each well was suspended in $200 \mu \mathrm{l}$ of Annexin V-Fluos (Roche Diagnostics, Mannheim, Germany) labelling solution and incubated at room temperature for $20 \mathrm{~min}$ in the dark. The labelling solution included incubation buffer with $10 \mathrm{mM}$ HEPES/NaOH (pH 7.4), $140 \mathrm{mM} \mathrm{NaCl}$ and $5 \mathrm{mM} \mathrm{CaCl}_{2}, 2 \mu \mathrm{l}$ of Annexin V-Fluos and $0.02 \mu \mathrm{g}$ propidium iodide (Roche Diagnostics, Manheim, Germany). Following this incubation, reaction was terminated by adding $400 \mu \mathrm{l}$ ice-cold PBS, and reaction products were measured in the Accuri C6 flow cytometer (BD Accuri Cytometers Ann Arbor, MI, USA).

\section{$\left[\mathrm{Ca}^{2+}\right]_{\text {free }}$ measurement in reticular fraction with fluorescent dye Rhod-5N}

We used the procedure as was described in Lencesova et al. (2013). Briefly, cells were scraped from wells, sedimented and washed with $1 \times$ PBS solution. Gentle lysis was performed with $100 \mu \mathrm{l}$ of cell lysis buffer from the kit for cytoplasmic and nuclear protein isolation (ProteoJetTM, Fermentas, Germany) and dithiothreitol to a final concentration of $1 \mathrm{mM}$. Pellets from the post-mitochondrial fraction were homogenized in nuclear lysis buffer from ProteoJetTM kit and pipetted to wells in a 24 -well plate. Rhod-5N fluorescent dye (Invitrogen Ltd., Paisley, UK) was added to each sample to a final concentration of $20 \mu \mathrm{M}$. Measurements were performed by the BioTek fluorescent reader (excitation $551 \mathrm{~nm} /$ emission $576 \mathrm{~nm}$ ). After measuring fluorescence (F), the signal was saturated by adding EGTA solution ( $\mathrm{pH}$ 7.0) to a final concentration of $2.5 \mathrm{mM}\left(\mathrm{F}_{\min }\right)$. The $\mathrm{F}_{\max }$ value was measured by adding $100 \mathrm{mM} \mathrm{CaCl}_{2}$ to a final concentration of $0.5 \mathrm{mM}$. The final values of $\left[\mathrm{Ca} 2^{+}\right]_{\text {free }}$ were calculated according to the formula: $\left[\mathrm{Ca}^{2+}\right]_{\text {free }}=\mathrm{K}_{\mathrm{d}}\left[\left(\mathrm{F}_{\max }\right.\right.$ $\left.-\mathrm{F}) /\left(\mathrm{F}-\mathrm{F}_{\min }\right)\right]$, where $\mathrm{K}_{\mathrm{d}}$ for Rhod $-5 \mathrm{~N}$ is $320 \mu \mathrm{M}$. Results were expressed as picomoles of calcium per microgram of protein.

\section{Microarray assay}

Total RNAs isolated from PC12 cells were purified with GeneJET $^{\text {TM }}$ RNA Purification Kit (ThermoScientific, USA) to eliminate copurified contaminants. Integrity of RNA was checked using BioAnalyzer RNA 6000 Nano Kit (Agilent Technologies, USA). Sample labeling reactions were performed using Quick Amp Labeling Kit (Agilent Technologies, USA). Briefly, $200 \mathrm{ng}$ of total RNA were primed with T-promoter primer and cDNAs were synthesized using MoMULV reverse transcriptase. In the next step Cy3/Cy5 labeled CTP was incorporated by amplification process and thus generated labeled cRNA. During this reaction, RNAs from RNA Spike-In kit (Agilent Technologies, USA) were added. Target was purified in order to remove nonincorporated nucleotides and reaction components using GeneJET ${ }^{\mathrm{TM}}$ RNA Purification Kit (ThermoScientific, USA). 825 ng of Cy3/Cy5 labeled samples and appropriate control samples were mixed together in hybridization reaction (Gene Expression Hybridization Kit, Agilent Technologies, USA) and were incubated $30 \mathrm{~min}$. at $60^{\circ} \mathrm{C}$, to fragment cRNA. Fragmented samples were applied on Agilent Rat Gene Expression $4 \times 44 \mathrm{k}$ v3 Microarray and hybridized $17 \mathrm{~h}$ at $65^{\circ} \mathrm{C}$ by rotating slide at speed $10 \mathrm{rpm}$. After that slides were washed in Wash buffers 1 and 2 (Gene Expression Wash Buffer Kit, Agilent Technologies, USA) and scanned at resolution of $5 \mu \mathrm{m}$, using Agilent scanner.

Image processing was performed using Feature Extraction Software 11.5 (Agilent Technologies, USA) and acquired files were imported into GeneSpring GX software to analyze difference in gene expression. During evaluation, only detected flags (significantly different from background) were subjected to analysis. Significant differences, considered in 
fold of change between treated and control samples, were $\geq 2$.0. Pathway analysis module was applied to revealed molecular pathways significantly affected in our experiment $(p<0.05)$.

\section{Statistical analysis}

Each value resulted from an average of 12 wells in at least 4 independent cultivations of PC12 cells. Results are presented as mean \pm S.E.M. Statistical differences between the groups were determined by ANOVA; ${ }^{* *} p<0.05$, ${ }^{* * *} p<0.001$ were considered as significant. An adjusted $t$ test with $\mathrm{p}$ values corrected by the Bonferroni method was used for multiple comparisons (Instat, GraphPad Software).

\section{Results}

In this work we verified that in PC12 cells, TTL (100 nM) applied for 24 hours caused significant increase in the NET protein (Figure 1A) and also in the transport of MIBG (Figure 1B) through this transport system. Moreover, reticular calcium in PC12 cells was significantly higher in TTL-treated cells compared to control, untreated PC12 cells (Figure 1C). Increase in the reticular calcium might be due to the altered expression of some calcium transport systems. Microarray analysis was used for an identification of gene/s, which may be involved in an increased reticular calcium and apoptosis in the cells treated with TTL. We have found that expression of SERCA 3 was significantly elevated (3.5-times), expression of RyR2 was decreased 2.3-times and expression of $\mathrm{IP}_{3}$ receptors of type 1,2 and 3 and other types of SERCA and RyR was not changed (ns;
Figure 2). Upregulation of SERCA 3 and decrease of RyR2 was also proved by the Western blot analysis (Figure 2) with appropriate primary antibodies.

As we have shown, reticular calcium was increased in TTL-treated cells and this increase was even more pronounced, when specific blocker of the $\mathrm{IP}_{3}$ receptors Xestospongin $\mathrm{C}(\mathrm{X})$ was added to TTL-treated cells (+X; Figure $3 \mathrm{~A})$. When xestospongin $\mathrm{C}$ was added to untreated cells, no increase in reticular calcium was observed compared to control group of cells (Figure 3A). Thapsigargin (TH) also did not reveal any change in the reticular calcium compared to untreated cells, but when thapsigargin was added to TTLtreated cells; it completely abolished TTL-induced increase in reticular calcium (Figure $3 \mathrm{~A}$ ). In the group of cells where TTL, thapsigargin and Xestospongin $\mathrm{C}$ were added at the same time, TTL-induced increase was also prevented $(+\mathrm{X}$, +TH; Figure 3A).

More importantly, apoptosis that was increased by TTL, was not affected, when xestospongin $\mathrm{C}$ was added to the TTL-treated cells (+X; Figure 3B). However, when the cells were treated in both TTL and TH $(+\mathrm{TH})$, TTL-induced increase in apoptosis was prevented (Figure 3B). When Xestospongin $C$ was added to cells in the presence of TTL, TTL-induced apoptosis remained on the same level as in the group treated only with the TTL (Figure 3B).

In the presence of glucose, number of Annexin $\mathrm{V}$ positive cells was higher in TTL-treated cells (Figure 4A). Also, Bax/ $\mathrm{Bcl} 2$ ratio, which is considered to be a marker of increased apoptosis, was higher on the level of gene expression (Figure $4 \mathrm{C}$ ). Protein levels of Bax and Bcl2 protein confirm this observation (Figure 4D). Nevertheless, when PC12 cells were incubated with 2-deoxyglucose, no change in apoptosis was observed in TTL-treated, compared to control cells (Figure 4B).
A

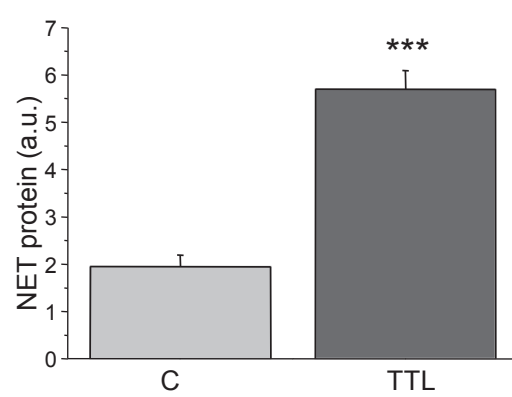

\section{B}

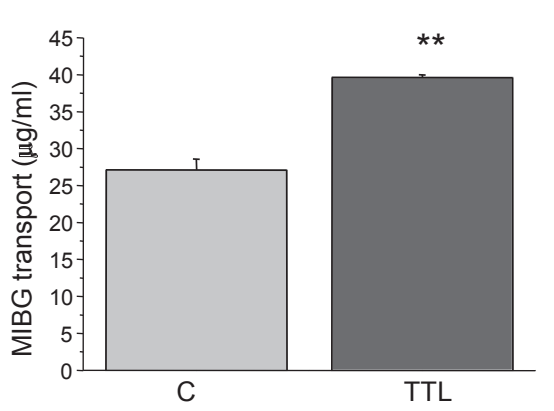

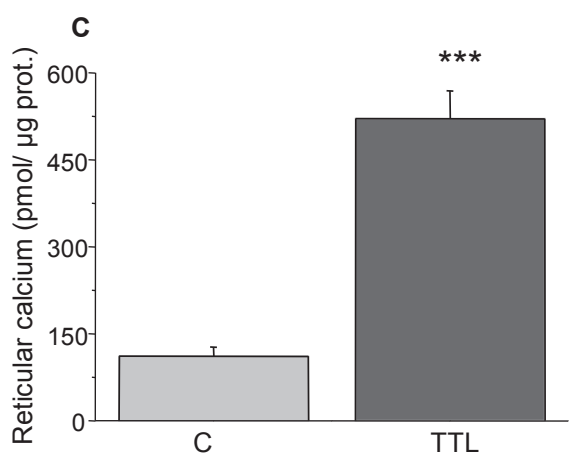

Figure 1. TTL-induced increase in the NET protein (A), MIBG transport (B) and amount of reticular calcium (C) in PC12 cells. Cells were treated with $100 \mathrm{nM}$ TTL for 24 hours. Results are presented as mean \pm S.E.M. and represent an average of triplicates from three cultivations. Statistical significance compared to controls was ${ }^{* *} p<0.01$ and ${ }^{* * *} p<0.001$. C, control; TTL, triptolide; NET, norepinephrine transporter; MIBG, metaiodobenzylguanidine. 


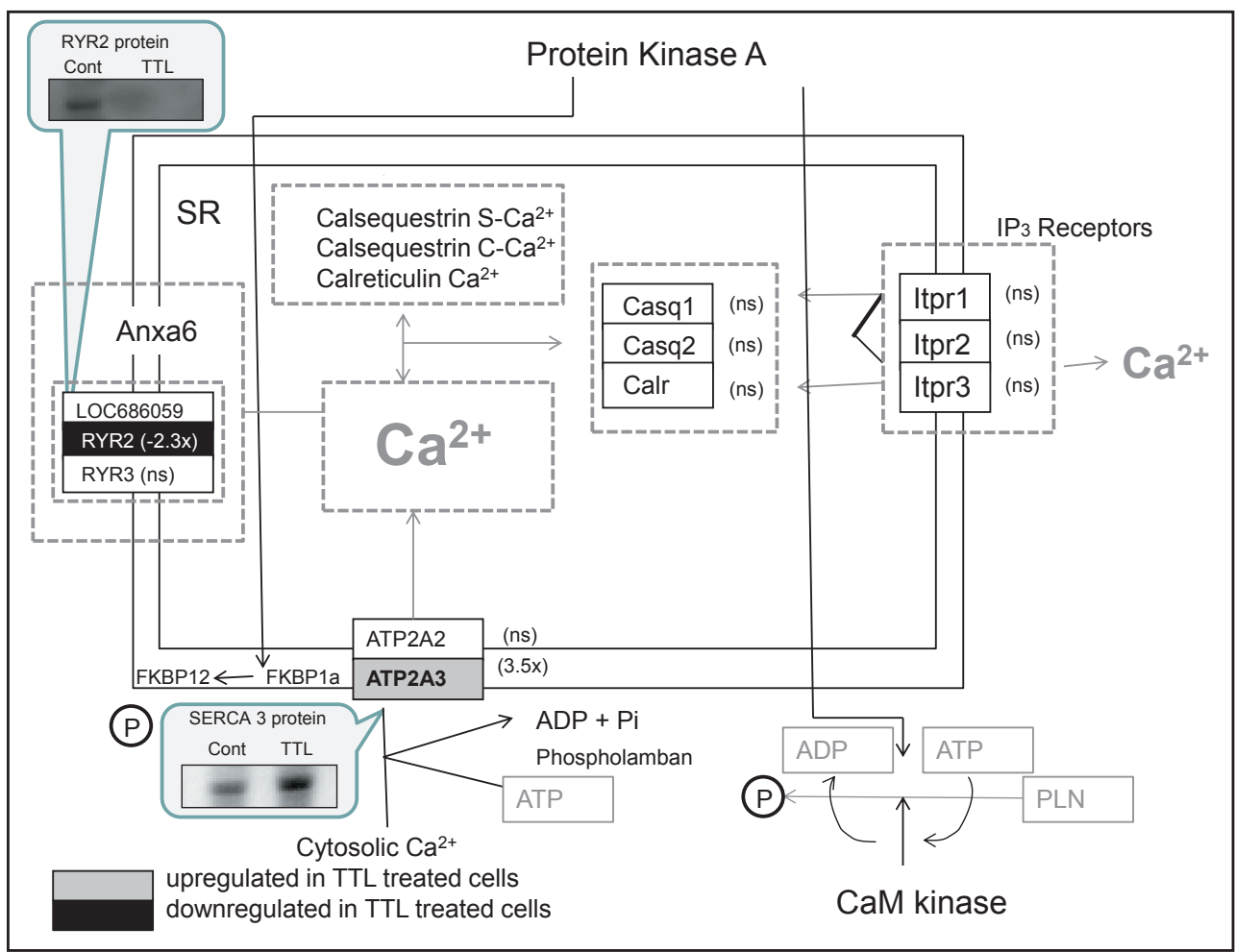

Figure 2. Gene profiling of reticular calcium transport systems and confirmation by Western blot analysis. Gene profiling was performed by microarray chip (Agilent) and is displayed as a fold of change in mRNA of TTL-treated, compared to control, untreated cells. Significant change was considered to be 2 -fold and more and is displayed in brackets. The ratio of mRNA of those genes, where no significant change was observed is marked (ns). In TTL-treated cells, SERCA 3 mRNA was increased 3.5-times and RyR2 mRNA was decreased 2.3-times compared to control, untreated cells. Increase in SERCA 3 and decrease in RyR2 was verified by Western blots using appropriate antibodies (see representative gels showing different intensities in control and TTL-treated cells). Abbreviations for genes corresponding to: calsequestrin (Casq), calreticulin (Calr), inositol 1,4,5-trisphosphate receptor (Itpr), phospholamban (PLN), annexin A6 (Anxa6), FK binding protein-protein folding chaperone (FKBP). SR, sarcoplasmic reticulum; Cont, control; TTL, Triptolide.

\section{Discussion}

In this work we have shown that TTL $(100 \mathrm{nM})$ increased significantly not only the NET protein and MIBG transport, but also the amount of reticular calcium. This raise was accompanied by the increase in pro-apoptotic parameters, such as $\mathrm{BAX} / \mathrm{Bcl} 2$ ratio or \% of Annexin V-positive cells. Elevation in the NET protein due to the TTL treatment was already shown in our previous work (Pacak et al. 2012). This increase nicely correlated with the amount of MIBG incorporated into the cells. MIBG serves as a potent diagnostic tool in determining pheochromocytomas and also as a potential therapeutic agent for this type of tumors (Gonias et al. 2009; Grunwald and Ezziddin 2010). Surprisingly, reticular calcium was also significantly increased after the TTL treatment. Thus, we performed microarray gene profiling to compare the expression of genes coding reticular calcium transport systems in control and TTL-treated PC12 cells. Unexpectedly, expression of genes coding all three types of
$\mathrm{IP}_{3}$ receptors was not changed by the TTL treatment, but expression of the SERCA 3 (but not SERCA 2) was increased and expression of the RyR2 was decreased. We verified this observation with corresponding protein levels and we observed consistent results in both, SERCA 3 and RyR2. This would explain increased levels of reticular calcium due to the TTL treatment.

SERCA 3 is about 75\% identical to either SERCA 1 or SERCA 2 (Lytton et al. 1991). SERCA 3 is involved in a calcium mobilization from the cytosol into the endoplasmic reticulum and is closely linked to metabolism, neuronal plasticity, gene transcription, cell growth, differentiation, apoptosis, protein folding and carcinogenesis. In several cell systems, SERCA 3 expression is selectively induced during differentiation, whereas during tumorigenesis and blastic transformation SERCA 3 expression is decreased (Arbabian et al. 2011). SERCA 3 is co-expressed with the SERCA $2 b$ that is ubiquitously expressed isoform thought to be involved in "housekeeping" functions. Functional maturation of ER calcium homeostasis 
A

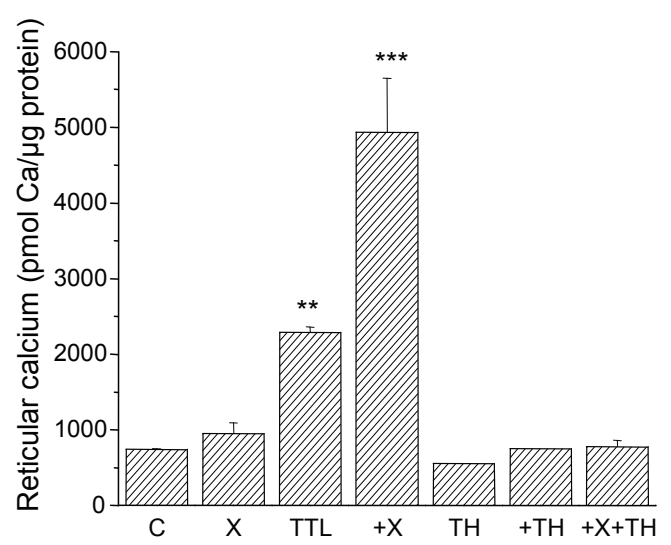

B

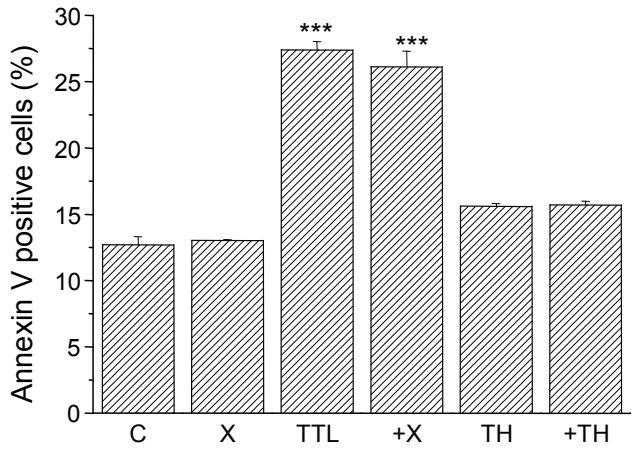

Figure 3. Modulation of the reticular calcium (A) and of number of apoptotic cells (B) by Xestospongin C (X; inhibitor of $\mathrm{IP}_{3}$ receptors) and thapsigargin (TH; SERCA blocker) in control and Triptolide (TTL)-treated PC12 cells. Neither X, nor TH alone change the amount of reticular calcium in control (C), untreated cells (A). TTL caused increase in reticular calcium content and this increase was potentiated by simultaneously added X $(+\mathrm{X} ; \mathrm{A})$. When cells were treated simultaneously with TTL and TH $(+\mathrm{TH})$, no change in reticular calcium was observed (A). TTL- induced apoptosis was not changed by X (+X), but was completely prevented by TH (+TH; B). Results are presented as mean \pm S.E.M. and represent an average of triplicates from three independent cultivations. Statistical significance compared to controls was ${ }^{\star *} p<0.01$ and ${ }^{* *} p<0.001$.

that occurs during normal cell differentiation is blocked due to deficient SERCA 3 expression in malignant cells and this phenomenon is involved in the maintenance of the neoplastic phenotype (Arbabian et al. 2013). Thus, increased expression of the SERCA 3 in the TTL-treated PC12 cells might participate in proapoptotic effect of TTL.

In order to verify involvement of the SERCA 3 in apoptosis, we measured \% of Annexin $\mathrm{V}$ positive cells in the group
A

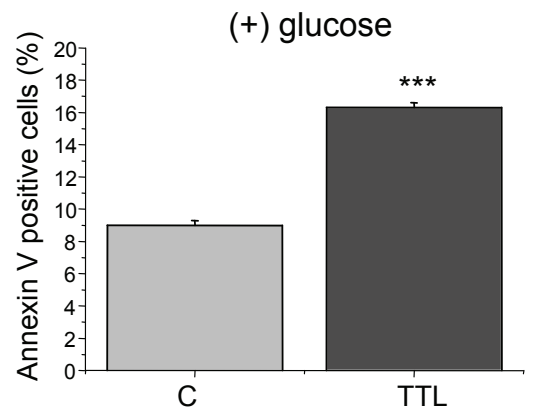

C

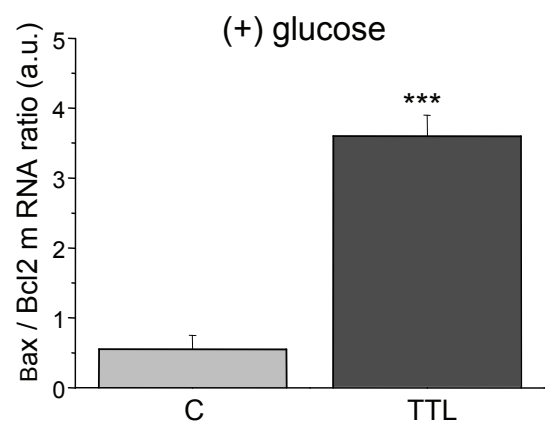

B

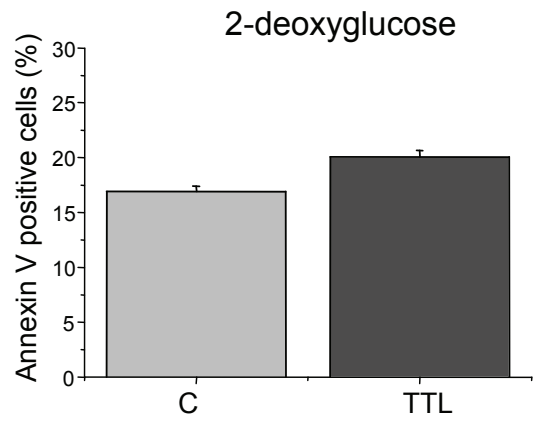

D

(+) glucose

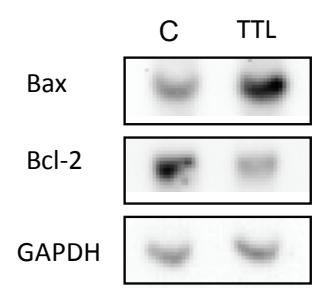

Figure 4. Comparison of the TTLinduced apoptosis in glucose and in 2-deoxyglucose medium. In glucose medium, TTL significantly increased apoptosis as determined by Annexin$\mathrm{V}$ Fluos (A) and also $\mathrm{Bax} / \mathrm{Bcl}$ ratio (C,D). In 2-deoxyglucose medium, TTL was not able to induce apoptosis (B). Results are presented as mean \pm S.E.M. and represent an average of triplicates from three independent cultivations. Statistical significance represents ${ }^{* *} p<0.001$ compared to controls. C, control; TTL, triptolide. 
of TTL-treated cells and TTL-treated cell in the presence of thapsigargin. Thapsigargin is non-competitive inhibitor of a class of enzymes known by the acronym SERCA, which stands for sarco/endoplasmic reticulum $\mathrm{Ca}^{2+}$ ATPase (Rogers et al. 1995). Thapsigargin inhibits all of the SERCA isoforms (Lytton et al. 1991). When PC12 cells were treated in the presence of TTL, number of apoptotic cells doubled. In the presence of TTL and Xestospongin C (a specific $\mathrm{IP}_{3}$ receptor's antagonist), no changes in apoptosis compared to TTL-treated group occur. However, treatment of PC12 cells in the presence of TTL and thapsigargin revealed apoptosis decreased to control levels. This observation clearly suggests that SERCA 3 upregulation is involed in an increase of a number of apoptotic cells. We propose that SERCA 3 expression is decreased in pheochromocytoma cells. TTL-induced increase in the expression of SERCA 3 might be a part of proapoptotic mechanism of this compound in PC12 cells. Our observations are in a good agreement with the work of Arbabian and co-workers (Arbabian et al. 2013) who have shown that the induction of SERCA 3 expression may exert anti-oncogenic effects in lung epithelial cells. However, the downstream mechanism of this effect remains still to be elucidated.

SERCA 3 belongs to the transport systems, which requires energy for its function. Replacement of glucose in the medium with 2-deoxyglucose, which is non-utilizable analog of glucose, markedly reduced the energy production and damped the function of SERCA, similarly to TH. Moreover, this stage is similar to the hypoxic environment in some tumors, where due to the decreased oxygen tumor cells rapidly decreased the production of ATP. We observed that in DMEM medium supplemented with glucose, TTL was capable to increase apoptosis rapidly, while in medium supplemented with 2-deoxyglucose was not able to upregulate apoptosis.

Thus, in summary we have shown that besides NF-kB blocking, SERCA 3 upregulation is required for the TTLinduced apoptosis in PC12 cells.

Acknowledgement. This work was supported by grants VEGA 0074/13, APVV-0045-11, Project implementation: KC: ITMS 26240220071, supported by the Research \& Development Operational Programme funded by the ERDF. Authors wish to thank to Dr. Danchenko for the help with MIBG determination.

\section{References}

Antonoff M. B., Chugh R., Skube S. J., Dudeja V., Borja-Cacho D., Clawson K. A., Vickers S. M., Saluja A. K. (2010): Role of Hsp-70 in triptolide-mediated cell death of neuroblastoma. J. Surg. Res. 163, 72-78

http://dx.doi.org/10.1016/j.jss.2010.04.047

Arbabian A., Brouland J. P., Apati A., Pászty K., Hegedus L., Enyedi A., Chomienne C., Papp B. (2013): Modulation of endoplasmic reticulum calcium pump expression during lung cancer cell differentiation. FEBS J. 280, 5408-5418

http://dx.doi.org/10.1111/febs.12064

Arbabian A., Brouland J. P., Gelebart P., Kovacs T., Bobe R., Enouf J., Papp B. (2011): Endoplasmic reticulum calcium pumps and cancer. Biofactors 37, 139-149

http://dx.doi.org/10.1002/biof.142

Cai Y. Y., Lin W. P., Li A. P, Xu J. Y. (2013): Combined effects of curcumin and triptolide on an ovarian cancer cell line. Asian. Pac. J. Cancer. Prev. 14, 4267-4271 http://dx.doi.org/10.7314/APJCP.2013.14.7.4267

Clawson K. A., Borja-Cacho D., Antonoff M. B., Saluja A. K., Vickers S. M. (2010): Triptolide and TRAIL Combination Enhances Apoptosis in Cholangiocarcinoma. J. Surg. Res. 163, 244-249 http://dx.doi.org/10.1016/j.jss.2010.03.067

Gonias S., Goldsby R., Matthay K. K., Hawkins R., Price D., Huberty J., Damon L., Linker C., Sznewajs A., Shiboski S., Fitzgerald P. (2009): Phase II study of high-dose [131I] metaiodobenzylguanidine therapy for patients with metastatic pheochromocytoma and paraganglioma. J. Clin. Oncol. 27, 4162-4168 http://dx.doi.org/10.1200/JCO.2008.21.3496

Grunwald F., Ezziddin S. (2010): 131I-metaiodobenzylguanidine therapy of neuroblastoma and other neuroendocrine tumors. Semin. Nucl. Med. 40, 153-163

http://dx.doi.org/10.1053/j.semnuclmed.2009.11.004

Hanson C. J., Bootman M. D., Roderick H. L. (2004): Cell signalling: IP3 receptors channel calcium into cell death. Curr. Biol. 14, 933-935 http://dx.doi.org/10.1016/j.cub.2004.10.019

Huang W., He T., Chai C., Yang Y., Zheng Y., Zhou P., Qiao X., Zhang B., Liu Z., Wang J., Shi C., Lei L., Gao K., Li H., Zhong S., Yao L., Huang M. E., Lei M. (2012): Triptolide inhibits the proliferation of prostate cancer cells and down-regulates SUMO-specific protease 1 expression. PLoS One 7, e37693 http://dx.doi.org/10.1371/journal.pone.0037693

Karin M. (2006): Nuclear factor-kappaB in cancer development and progression. Nature, 441, 431-436 http://dx.doi.org/10.1038/nature04870

Krosch T. C., Sangwan V., Banerjee S., Mujumdar N., Dudeja V., Saluja A. K., Vickers S. M. (2013): Triptolide-mediated cell death in neuroblastoma occurs by both apoptosis and autophagy pathways and results in inhibition of nuclear factor-kappa B activity. Am. J. Surg. 205, 387-396 http://dx.doi.org/10.1016/j.amjsurg.2013.01.008

Ku C. M., Lin J. Y. (2013): Anti-inflammatory effects of 27 selected terpenoid compounds tested through modulating Th1/Th2 cytokine secretion profiles using murine primary splenocytes. Food. Chem. 141, 1104-1113 http://dx.doi.org/10.1016/j.foodchem.2013.04.044

Kupchan S. M., Schubert R. M. (1974): Selective alkylation: a biomimetic reaction of the antileukemic triptolides? Science 185, 791-793 http://dx.doi.org/10.1126/science.185.4153.791

Lee H. F., Lee T. S., Kou Y. R. (2012): Anti-inflammatory and neuroprotective effects of triptolide on traumatic brain injury in rats. Respir. Physio. Neurobiol. 182, 1-8 http://dx.doi.org/10.1016/j.resp.2012.01.016 
Lencesova L., Hudecova S., Csaderova L., Markova J., Soltysova A., Pastorek M., Sedlak J., Wood M. E., Whiteman M., Ondrias K., Krizanova O. (2013): Sulphide signalling potentiates apoptosis through the up-regulation of IP3 receptor types 1 and 2. Acta Physiol. (Oxford) 208, 350-361 http://dx.doi.org/10.1111/apha.12105

Lencesova L., Krizanova O. (2012): IP(3) receptors, stress and apoptosis. Gen. Physiol. Biophys. 31, 119-130 http://dx.doi.org/10.4149/gpb_2012_014

Leuenroth S. J., Crews C. M. (2005): Studies on calcium dependence reveal multiple modes of action for triptolide. Chem. Biol. 12, 1259-1268 http://dx.doi.org/10.1016/j.chembiol.2005.09.009

Leuenroth S. J., Okuhara D., Shotwell J. D., Markowitz G. S., Yu Z., Somlo S., Crews C. M. (2007): Triptolide is a traditional Chinese medicine-derived inhibitor of polycystic kidney disease. Proc. Natl. Acad. Sci. U.S.A. 104, 4389-4394 http://dx.doi.org/10.1073/pnas.0700499104

Lowry O. H., Rosebrough N. J., Farr A. L., Randall R. J. (1951): Protein measurement with the Folin phenol reagent. J. Biol. Chem. 193, 265-275

Lytton J., Westlin M., Hanley M. R. (1991): Thapsigargin inhibits the sarcoplasmic or endoplasmic reticulum Ca-ATPase family of calcium pumps. J. Biol. Chem. 266, 17067-17071

MacKenzie T. N., Mujumdar N., Banerjee S., Sangwan V., Sarver A., Vickers S., Subramanian S., Saluja A. K. (2013): Triptolide induces the expression of miR-142-3p: a negative regulator of heat shock protein 70 and pancreatic cancer cell proliferation. Mol. Cancer Ther. 12, 1266-1275 http://dx.doi.org/10.1158/1535-7163.MCT-12-1231
Pacak K., Sirova M., Giubellino A., Lencesova L., Csaderova L., Laukova M., Hudecova S., Krizanova O. (2012): NF-кB inhibition significantly upregulates the norepinephrine transporter system, causes apoptosis in pheochromocytoma cell lines and prevents metastasis in an animal model. Int. J. Cancer 131, 2445-2455 http://dx.doi.org/10.1002/ijc.27524

Rogers T. B., Inesi G., Wade R., Lederer W. J. (1995): Use of thapsigargin to study $\mathrm{Ca} 2+$ homeostasis in cardiac cells. Biosci. Rep. 15, 341-349 http://dx.doi.org/10.1007/BF01788366

Wang Z., Jin H., Xu R., Mei Q., Fan D. (2009): Triptolide downregulates Rac1 and the JAK/STAT3 pathway and inhibits colitis-related colon cancer progression. Exp. Mol. Med. 41, $717-727$ http://dx.doi.org/10.3858/emm.2009.41.10.078

Wen H. L., Liang Z. S., Zhang R., Yang K. (2013): Anti-inflammatory effects of triptolide improve left ventricular function in a rat model of diabetic cardiomyopathy. Cardiovasc. Diabetol. 12,50 http://dx.doi.org/10.1186/1475-2840-12-50

Yang S., Chen J., Guo Z., Xu X. M., Wang L., Pei X. F., Yang J., Underhill C. B., Zhang L. (2003): Triptolide inhibits the growth and metastasis of solid tumors. Mol. Cancer Ther. 2, 65-72

Yu D. Q., Zhang D. M., Wang H. B., Liang X. T. (1992): Structure modification of triptolide, a diterpenoid from Tripterygium wilfordii. Yao Xue Xue Bao. 27, 830-836 (in Chinese)

Received: November 21, 2013

Final version accepted: January 13, 2014 